LITERATURA 



\section{EL ARTE NUEVO DE HACER... KABUKI: LAS TEORÍAS LOPESCAS SOBRE EL TEATRO Y SUS PARALELISMOS EN EL KABUKI NIPÓN}

Fernando Cid Lucas

Para Irene

\section{RESUMEN}

En el presente trabajo se recogen las ideas principales propuestas en el Arte nuevo de hacer comedias en este tiempo (1609), de Félix Lope de Vega y Carpio (1562-1635), y las coincidencias de estas con la poética del teatro Kabuki, con el que comparte muy interesantes paralelismos.

Palabras clave: Teatro, corral de comedia, Kabuki, poética, Barroco.

\section{ABSTRACT}

This paper examines the main proposals in El arte nuevo de hacer comedias en este tiempo (1609), written by Félix Lope de Vega y Carpio (1562-1635), and the coincidences of these with the inner manner in Kabuki, with which it shares interesting resemblances.

Key words: Theatre, corral de comedia, Kabuki, inner manner, Baroque.

\section{Introducción}

Fue al recientemente fallecido Ricard Salvat (1934-2009) a quien en una magnífica conferencia escuché decir que las poéticas, antes que para ser aceptadas o no, están para ser discutidas. Partiendo de esa aparentemente sencilla premisa quiero encauzar el discurso de mi artículo, en el que se expondrán de forma somera las ideas defendidas por Félix Lope de Vega en su tratado en verso titulado Arte nuevo de hacer comedias en este tiempo ${ }^{1}$ y las posibilidades

Fernando Cid Lucas. Licenciado en Filología. Miembro Investigador y Secretario del GIR "Recepción del imaginario Japonés" de la Universidad de Valladolid y Miembro de la Asociación Española de Orientalistas, Universidad Autónoma de Madrid.

Correo electrónico: fernandocidlucas@gmail.com

Recepción: 27- 2- 2009

Aceptación: 2- 4- 2009 
de los principios lopescos allí recogidos para encajar en la preceptiva del teatro Kabuki, más en concreto en el desarrollado durante los siglos XVII y XVIII, época en la que alcanzó su mayor reconocimiento popular y cuando los mejores dramaturgos del país compusieron sus obras para él.

\section{Lope y su Arte nuevo de hacer comedias}

No seré yo el que argumente ahora la importancia que el pequeño tratado en verso de nuestro genial "fénix de los ingenios" (de apenas 400 versos) tuvo para el futuro del teatro español. Estudios firmados por profesores tan autorizados como Juan de José2 ${ }^{2}$ Erwin Haverbeck ${ }^{3}$ o Juan Manuel Rozas ${ }^{4}$ servirían mejor para esta causa. Sin embargo, no estará de más señalar algunos de sus aspectos fundamentales para comprender mejor las intenciones de este trabajo.

Como indicaba, a pesar de su breve extensión, ni las intenciones del tratado ni su contenido son baladíes. Dirigido y leído ante la Academia de Madrid ${ }^{5}$, el texto del Arte nuevo de hacer comedias en este tiempo merece con toda justicia ser incluido entre los títulos dedicados a la teoría teatral firmados por autores clásicos, tales como Aristóteles u Horacio o posteriores a él, como Denis de Diderot y su Paradoxe sur le comédien (¿1769?).

Como han apuntado diferentes especialistas ${ }^{6}$, Lope de Vega deja marcadas unas intenciones muy precisas en su tratado, a la vez que plantea unas reformas escénicas -dejando siempre los cabos bien amarrados- que se oponen sustancialmente a la manera de entender el teatro de autores inmediatamente anteriores a su generación, como el mismísimo Miguel de Cervantes (1547-1616) o Lupercio Leonardo de Argensola (1559-1613).

Convertido en autor de éxito en la época en la que compone su Arte Nuevo, a él y a sus discutidos planteamientos allí expuestos se dirigieron autores contemporáneos, como el dicho Cervantes en su obra más representativa El Ingenioso Hidalgo Don Quijote de la Mancha:

\footnotetext{
-Decidme, ¿no os acordáis que ha pocos años que se representaron en España tres tragedias que compuso un famoso poeta destos reinos, las cuales fueron tales que admiraron, alegraron y suspendieron a todos cuantos las oyeron, así simples como prudentes, así del vulgo como de los escogidos, y dieron más dineros a los representantes ellas tres solas que treinta de las mejores que después acá se han hecho?_Sin duda -respondió el autor que digo- que debe de decir vuestra merced por La Isabela, La Filis y La Alejandra. - Por esas digo -le repliqué yo-, y mirad si guardaban bien los preceptos del arte, y si por guardarlos dejaron de parecer lo que eran y de agradar a todo el mundo. Así que no está la falta en el vulgo, que pide disparates, sino en aquellos que no saben representar otra $\operatorname{cosa}^{7}$.
}

Dentro de sus proposiciones escénicas, que primero cristalizarán en la redacción de la mayor parte de sus comedias ${ }^{8}$ y luego en las de otros dramaturgos, como Juan Pérez de Montalbán (1602-1638) o Tirso de Molina (1579-1648), una de las más importantes, en cuanto a aspectos formales se refiere, es la reducción de los cuatro actos acostumbrados hasta ese momento a tres. Reajuste que, según nos dice el propio Lope, realizó el dramaturgo y militar valenciano Cristóbal de Virués ${ }^{9}$ (1550-1614) por vez primera, aunque luego la perfeccionaría nuestro "fénix" y la emplearía en sus numerosas comedias.

En cuanto a la aceptación de la unidad de tiempo, tesis defendida por Aristóteles en su Poética, también fue de Virués de quien Lope bebiese para elaborar obras que se desarrollan en distintos lapsos (debemos señalar que el argumento de La gran Semíramis, acaso obra cumbre del valenciano, transcurre a lo largo de veintidós años). Por contra, humanistas como 
Francesco Robortello (1516-1567) abogaban porque el argumento se resolviese en poco más de un día y sin complicaciones temporales.

En cambio, en relación a la unidad de acción en apenas ocho versos Lope acepta, defiende y despacha el principio aristotélico, alegando que si éste se altera o no se dota de una estructura homogénea al texto no se logrará un interés general o una armonía de conjunto:

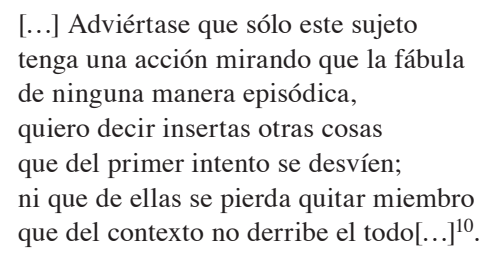

Entrando ya en comparaciones entre Oriente y Occidente, es esta de la unidad de tiempo una teoría que defenderán dramaturgos nipones de la talla de Monzaemon Chikamatsu (1653-1725) o Nakamura Tamasuke (1778-1838), quizá no en obras teóricas como la de Lope, ya que, como ha escrito el profesor Jaime Fernández sobre esto: “[En Japón] en [esta] época no se sentía la urgencia de hacerlo, y cada autor proseguía su actividad creadora sin concienciarse como una entidad peculiar independiente de los demás"11, pero sí siendo consecuente con este principio en su producción dramática. Así, en obras como Hakkeden (estrenada en 1836), comprobaremos que el citado Tamasuke respeta escrupulosamente las secuencias de la acción, facilitando al auditorio la comprensión de una trama ya de por sí complicada (dividida en numerosos actos y escenas).

En lo que están de acuerdo tanto el dramaturgo madrileño como muchos autores de Kabuki es en la no contemplación de la unidad de lugar (a la que, por cierto, no hace alusión directa el propio Aristóteles en su Poética, siendo una invención de los aristotélicos renacentistas, de comentaristas de la obra del estagirita como Vincenzo Maggi ${ }^{12}$ (1498-1564) o Bartolomeo Lombardi (h.1505-h.1542). En el Kabuki, casi podría ser una constante los innumerables cambios de ambientación, incluso dentro de las mismas escenas. Por medio de un complicado aparato escénico descubriremos verdaderos prodigios, como mutaciones repentinas de decorados o súbitas apariciones y desapariciones de actores. Con estos artificios se consigue hacer creíble que los personajes viajan a lugares lejanos o, incluso, que en cuestión de segundos se desplazan hasta el cielo o a los infiernos. Ni que decir tiene que estos prodigios admiraron al público de aquí y de allí, un público que casi acudía al teatro para ser sorprendido por las tramoyas ${ }^{13}$ más que por el uso de la palabra. Aunque, vayamos por partes.

\section{Nacimiento del Kabuki}

Fue a principios del siglo XVII cuando esta forma teatral surgió en Kyoto, antigua capital del Imperio del Sol Naciente hasta su traslado definitivo a Tokyo en 1868. Allí, una hermosa jovencita llamada Okuni (sirviente del templo de Izumo) y sus compañeras hicieron de sus reuniones informales en la orilla del río Kamo el germen de lo que luego sería una de las señas de identidad del Japón, junto con el sumō o el ikebana. Y es que, al poco de que Okuni y sus muchachas comenzasen a actuar, combinando en sus funciones la danza, la música y la parodia del teatro que se hacía en palacio, encontraron en la clase trabajadora de la zona $\left(\right.$ chōnin $\left.^{14}\right)$ un inmejorable mecenas. 
Tras la prohibición gubernamental en 1610 de la compañía de Okuni, debido a acusaciones que afirmaban que la joven ejercía la prostitución tras las funciones, con la supresión completa de la mujer en los escenarios en 1629 y la de los jovencitos en 1652 por los mismos motivos, parecía que la vida del Kabuki corría peligro. En absoluto. Aunque actrices y jóvenes actores habían sido condenados y desterrados y su público estaba en el punto de mira de las autoridades, el Kabuki había calado ya profundamente entre la pujante clase media japonesa y se había convertido en su pasatiempo favorito. De los bolsillos de los chōnin saldría el dinero para pagar los salarios de dramaturgos, actores y tramoyistas, o para sufragar las construcciones de los primeros teatros estables. Así, pues, parecía más que lógico que, ya que el pueblo pagaba, los escritores compusiesen sus piezas atendiendo a su gusto, y que los actores representasen teniendo en cuenta que era lo que estos querían ver ${ }^{15}$. Sí existió, sin embargo, una dura y dilatada persecución de estos dramaturgos por parte de la censura que, alentada por los estrictos dirigentes neoconfucionistas, intentó por todos los medios coartar muchas de las piezas del repertorio, debido a que los dramas en los que se aludía a personajes históricos estaban estrictamente prohibidos. Uno de los recursos más frecuentes entonces era cambiar el nombre de los protagonistas y ambientar la historia en un tiempo remoto. Aún así, muchas veces la obra se retiraba de la programación y los dramaturgos y los empresarios debían pasar por la comisaría más cercana.

\section{Las poéticas no escritas (aunque bien aceptadas) del Kabuki}

\subsection{Cuestiones previas}

Como indicaba en el apartado anterior, a partir de 1652, cuando los chōnin asuman por completo los gastos derivados del Kabuki, sus dramaturgos compondrán sus obras pensando siempre en complacerlos, dejando aparte cuestiones de estilo o, incluso, de decoro. En este sentido, es pertinente indicar que el Kabuki difiere en todo al teatro desarrollado en las cortes y monasterios de Japón, el denominado $N \bar{o}$. El $N \bar{o}$ es un espectáculo elevado, estático. Seguramente, el público que por aquellos años se divertía asistiendo a las populosas y ruidosas representaciones de Kabuki se habría aburrido de manera soberana en una representación de $N \bar{o}$, donde los movimientos, la música y la palabra se ejecutan lenta y repetitivamente durante horas y donde la acción es mínima.

Sin embargo, esta clase emergente, estos "nuevos ricos" con un poder económico cada vez más pujante, se encargarían de reglar casi sin quererlo los principios estéticos y artísticos del periodo Genroku (1688-1704), dando lugar al movimiento denominado Ukiyo o Mundo Flotante, en el que se celebraba la alegría de vivir, sin preocuparse de cuestiones profundas o complicadas. En palabras del profesor Federico Lanzaco Salafranca:

[...] UKIYO es vivir el presente, gozando de lo que tienes a tu alcance, sin preocuparte de lo que te espera mañana. Este principio es lo que te mantendrá a flote, sin hundirte en el curso de su existencia... hasta el momento final del que no debes preocuparte, porque ¡no puedes evitarlo! Naturalmente, este placentero mundo de la diversión cuesta dinero. Y los únicos ciudadanos en este periodo de la sociedad Edo que controlaban las finanzas y la liquidez del país eran los pudientes comerciantes [... $]^{17}$.

En efecto, en el mismo grupo que el Kabuki podríamos catalogar las novelas libertinas de Ihara Saikaku (1642-1693) o los bellísimos ukiyo-e de grabadores como Kitagawa Utamaro 
(h.1753-1806) o Katsushika Hokusai (1760-1849). En todas estas manifestaciones artísticas veremos latentes esas ganas desaforadas de vivir y de disfrutar el momento, riéndose casi de la muerte y de la podredumbre humana; y, como sucede en el género teatral al que ahora nos referimos, encontraremos los mismos patrocinadores tras ellos: los chōnin.

Orgullosos y sabedores de su poder, los chōnin querrán para las funciones de Kabuki héroes salidos del pueblo, formados a sí mismo, cuyo valor e inteligencia es reconocido incluso por los nobles. Así, como sucede en muchas comedias de Lope, los comerciantes que acuden al teatro se deleitan con obras en las que el héroe es un hijo del pueblo, nadie ornado por títulos que le vienen de nacimiento.

En los muy comentados versos de Lope que dicen:

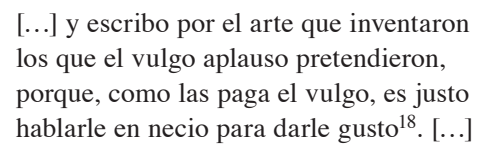

El dramaturgo madrileño concluye y da poco margen de interpretación a la crítica sobre a quién van dirigidas sus comedias, fijando su atención en la plebe, sobre quienes recaía la labor de sufragar el espectáculo (salarios, obras y mejoras en los teatros, etc.). Las denominadas hermandades (auténticas predecesoras de los empresarios teatrales de hoy en día), salidas de los gremios de profesionales medievales, aportaban el dinero para la programación anual de los corrales de comedias.En este mismo ámbito actuaban en Japón los citados chōnin, quienes, además de su contribución a los templos cercanos, dedicaban una nada desdeñable suma anual al mundo del teatro.

Por ello, como dice el profesor Hidehito Higashitani: “[en el Kabuki] lo más importante es agradar al «vulgo» y contar con el apoyo definitivo del público". Técnicamente, desde la elaboración del texto dramático esto se conseguía con las denominadas "Tres Amabilidades". Kawatake Mokuami (1816-1893), acaso el último gran compositor de piezas para el Kabuki, si salvamos honrosas excepciones como el escritor Yukio Mishima (1925-1970), fue quien mejor explicase y llevase a cabo esta teoría, que consiste en: "ser amable en la misma medida con los actores, con el público y con el empresario". Leyendo esta aseveración, descubrimos que las clases dominantes quedaron deliberadamente excluidas de la vida teatral, siendo meros invitados, pero no parte activa de ella. Es ahora cuando samuráis y terratenientes se "amoldan" a un mundo que se articula y triunfa sin ellos y que, con el pasar de los años, llegará a ser marca de identidad del Imperio del Sol Naciente. No en vano, Chikamatsu, el denominado Shakespeare nipón, acuñó una certera frase que indicaba un claro cambio de mentalidad entre los viejos tiempos y los nuevos. Dice: "El camino del samurái no es el único camino, existe también el camino del chōnin".

\subsection{Preferencias teatrales}

Una de las ramas de las obras Kabuki está formada por las denominadas sewamono (世話物) u obras del pueblo, opuestas a las jidaimono (時代物) u obras de ambientación histórica. Las sewamono tienen siempre como protagonistas a los propios chōnin, a mercaderes, campesinos o prostitutas en un escenario alejado también de la ambientación palaciana y fijado en los barrios humildes de las ciudades (sobre todo Osaka y Kyoto). Sin embargo, subyace en estas piezas un profundo respeto hacia la honra y la obligación para 
con la familia y con la comunidad. Si observamos con detenimiento el corpus conservado, comprobaremos que éste será uno de los temas tratados por Lope de Vega en algunas de sus comedias más famosas, como Peribañez y el comendador de Ocaña (1614) o Fuenteovejuna (1610).

Se sobrentiende que la gente de la corte debía condenar públicamente estas obras, pero asistían a ellas de forma furtiva cada noche, muchas veces disfrazados de plebeyos y pagando una buena suma de dinero por ocupar uno de los discretos palcos separados del vulgo; y, sin duda, allí disfrutaban, imbuidos por un ambiente mucho más relajado e informal que el de palacio.

Estos dramas sobre la honra villana eran muy seguidos en Japón. Está constatado que el público sufría con los progresos de sus protagonistas, que gritaban e, incluso, que arrojaban a los enemigos holgadas "ofrendas de pepinos", que diría Cervantes, como si quisiesen ser ellos mismos parte de la función.

Uno de los grandes compositores de estas obras fue el citado dramaturgo Monzaemon Chikamatsu, quien se especializó en ellas y, más en concreto, en una especie de subgénero, los denominados shinjūmono, obras en las que los amantes, ante la incapacidad de poder llevar a buen puerto su historia de amor, deciden suicidarse de forma ritual. Chikamatsu sabía que el público amaba y pedía shinjūmonos temporada tras temporada, por lo que llegó a escribir once de estos dramas, en los que se exponía abiertamente el asunto del ninjo, u obligación social del individuo para con la colectividad (aún en profesiones tan mal consideradas, como las prostitutas o los usureros); algo con lo que todos deben cumplir, un trato que a ninguna costa debe romperse. Ni que decir tiene que los tristes enamorados, por muy apasionado que se muestre su amor, también participan de esta transacción moral.

Profundo conocedor de la idiosincrasia nipona, el profesor Lanzaco nos da la solución ante la problemática que plantea el ninjō (y con ella revela al lector o al espectador de dichas obras su inefable resolución):

\footnotetext{
i) cumplir fielmente "la obligación" sacrificando "los sentimientos"; ii) desligarse de la obligación social y dejarse llevar por los sentimientos personales. Y como ninguna de estas alternativas son "viables" realísticamente en la sociedad Edo, solamente era aceptable la alternativa iii) del suicidio. Así se honra a la obligación y no se cercenan los sentimientos. Es la alternativa de un corazón sincero (makoto) ${ }^{21}$.
}

Como ya hemos dicho, a diferencia de lo que se hacía en el $N \bar{o}$, donde valientes guerreros, nobles o divinidades eran los protagonistas, otra de las novedades que el Kabuki proponía era la de colocar ante el espectador a estos miembros del pueblo llano, pero otorgándoles bellas palabras y profundos sentimientos capaces de conmover al auditorio. Así, el público sentía cercana aquellas historias que tenían lugar en los barrios que ellos mismos transitaban cada día y les eran comunes nombres propios típicos de la gente sencilla. Como dice el gran hispanista Hidehito Higashitani: "No cabe duda de que para el público en general el Kabuki ofrecía un medio ideal para olvidarse momentáneamente de los sinsabores de la vida mientras asistían a la representación ${ }^{22}$ ". Idéntica definición que podríamos emplear para definir los espectáculos teatrales ibéricos de los siglos XVII y XVIII.

Otra diferencia notable se encuentra en el hecho de hacer coincidir a personajes de rango elevado con plebeyos, algo que nunca fue problema en las tablas niponas, donde podríamos encontrar ya en el $N \bar{o}$ que los nobles o las mismas deidades (shite ${ }^{23}$ ) necesitaban de campesinos y pescadores $\left(w a k i^{24}\right)$ para "alumbrar" sus parlamentos, ya que los interlocutores de alta alcurnia no deben nunca hablar en exceso, por ser la charlatanería un rasgo propio del pueblo llano. Sin embargo, este teatro cortesano no nos presentará a los campesinos con sus 
trajes de faena o sudorosos después de una dura tarea, sino que los recubrirá con el esplendor propio de la corte, vistiendo delicados kimonos, portando hermosas máscara de madera de ciprés sobre sus rostros y expresándose de forma docta. Por el contrario, en nuestros parámetros, hasta la llegada de Lope, las castas sociales apenas si se "tocaban" sobre los escenarios. Podríamos decir entonces que las piezas versaban sobre nobles o sobre villanos. No existe en Lope una separación de obras atendiendo a la escala social de sus protagonistas, aunque si es más que evidente una consciente caracterización a la hora de darles un registro lingüístico o de especificar su vestuario, sus ademanes, etc. Tales argumentos tocantes a la coherencia de los rasgos de los personajes no eran, sin embargo, nuevos en Europa. Algo más de un siglo antes de la redacción del arte nuevo el humanista y dramaturgo vicentino Giovanni Giorgio Trissino (1478-1550) había teorizado sobre estos asuntos en sus seis libros titulados La Poética (1529-1562) de una manera parecida a la ideada luego por Lope:

Il costume poi particolare, che si dimanda retorico, si considererà in questo modo: o secondo le nazioni, o secondo i paesi, o secondo il genere, o secondo la età, o la fortuna, o le disposizioni, o gli essercizii, le quali sette parti comprendeno tutti e costumi particolari ${ }^{25}$.

Afirmaciones que tienen su paralelismo y glosa en nuestro idioma en los versos del Arte nuevo:

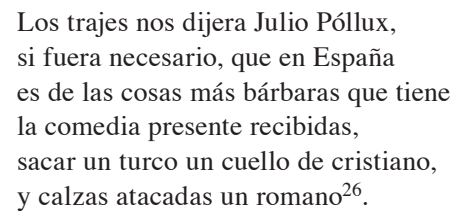

Y la misma coherencia se pide en el vestuario a los actores del Kabuki, para quienes su vestimenta representa parte importante de la identidad del personaje sobre el escenario ${ }^{27}$. Para cada uno existe un tipo justo de vestido, una forma de lucirlos y aún unos colores y unos estampados determinados para los tejidos (como sucede en los maquillajes faciales o kumadori). Para algunos actores, como el reverenciado Ichikawa Danjūrō IX (1838-1903), no respetar estos preceptos suponía romper con una de las normas fundamentales de este arte y una grave ofensa contra él. Tampoco aquí hay problema en que concurran a la vez nobles y villanos, eso sí, dejando actuar la semiótica de vestidos, maquillajes y otros atrezos ${ }^{28}$ para marcar las distancias.

Por otro lado, la intriga paralela, un rasgo tan netamente lopesco ${ }^{29}$, es otro de los elementos compartidos entre ambos espectáculos. Es más, en algunos títulos del Kabuki tardío (finales del XIX y primeros años del XX), incluso podríamos hablar de que existen dos o más tramas a un mismo nivel de importancia. Por ejemplo, en Yoshitsune Senbon Zakura, tan interesante resulta seguir las aventuras del héroe Yoshitsune como las de uno de los personaje secundarios, el zorro Genkurogitsune.

\section{Un espacio para el teatro}

Otra de las características que comparte el Kabuki con nuestro teatro barroco, hecho en los corrales de comedias, es el del lugar donde se representan las funciones. Así, los edificios que las albergan se encuentran situados físicamente en el corazón de las ciudades, participando activamente de la vida económica de las mismas, junto a lonjas y negocios. Sustancialmente, 
el teatro era una fuente de ingresos fija e importante para la comunidad y, con el tiempo, casi indispensable para esta. Localizados en los denominados akubasho o "malos lugares", compartían ubicación con tabernas y prostíbulos (cuando no se mezclaban estos oficios en un mismo edificio), dando lugar a los kuruwa o "barrios del placer". Nombres tan sugerentes como Yoshiwara en Tokyo, Shimabara en Kyoto o Shinmachi en Osaka, sirvieron de cuna a prestigiosos teatros, luego trasladados, con el progresivo reconocimiento social del teatro, a los enclaves más prestigiosos de la urbe.

Apartándonos un tanto del motivo principal de este ensayo, indicaremos que el teatro era un lugar bullicioso, de encuentro, que servía para cerrar tratos, para encontrarse con amigos y para descansar (o "desconectar", usando un término más actual), en el que se veía y, a veces, se lograba escuchar teatro. Tanto japoneses como ibéricos comían y bebían en el interior, gritaban a sus actores favoritos y, algunos, buscaban bronca. En una muy bella película de Hiroshi Hinagaki, titulada El hombre del carrito (1958), podemos ver al principio de su metraje cómo era la vida interior en una de estas salas dedicadas al Kabuki, en donde se cocinaba y el humo molestaba a los vecinos o donde se lucían vestidos y peinados para dar envidia a las vecinas. Sin ser un experto en estos asuntos, muy parecido debió ser el interior de los corrales de comedias de España y Portugal, donde la zona destinada a las mujeres recibía el nombre de "gallinero" y el patio quedaba para los "mosqueteros".

\section{Apéndice. Apuntes para un estudio comparado entre Chüshingura y Fuenteovejuna}

Como ha sugerido ya el catedrático Jaime Fernández, existen ciertos paralelismos entre algunas obras para Kabuki y las escritas por Lope de Vega, refiriéndose, por ejemplo, a $E l$ asesino de una mujer, de Monzaemon Chikamatsu y La fianza satisfecha, del autor madrileño. Sin embargo, en esta pequeña coda voy a hablar muy brevemente de las similitudes entre una de las piezas más famosas del repertorio del Kabuki ${ }^{30}$, Kanadehon Chūshingura, de los dramaturgos Takeda Izumo II, Miyoshi Shōraku y Namiki Senryū, con otra de las habituales del repertorio lopesco: Fuenteovejuna, que, en palabras del profesor Rinaldo Froldi: "parece corresponder a las características que el propio Lope perfiló en su Arte Nuevo 31 ".

Aunque durante mucho tiempo la obra nipona se vio como la exposición de los lances heroicos dignos de admiración de los samuráis del daimyõ de Akõ, la crítica ha visto en la pieza un alegato social y reivindicativo. En ambas piezas dos planos sociales están claramente enfrentados desde sus primeras líneas y en las dos el elemento vengador surge de una casta inferior (del pueblo en su significado más amplio en España y de los rōnin o samuráis sin señor en Japón).

Tanto en una como en otra, el desencadenante del conflicto es un personaje que abusa de su posición y se aprovecha de ella, o de su "intocabilidad", si deseamos afinar aún más. Arrogante y pretencioso, el comendador de Lope (lo mismo que podría hacer el maestro de ceremonia de Chūshingura) hace ostentación de su posición en versos como:

[...] Cuando no sepa mi nombre,

¿no le sobra el que me dan

De comendador mayor? $[\ldots]^{32}$ 
Siguiendo con este pequeño análisis textual, los versos que recita Esteban, el alcalde de la localidad en Fuenteovejuna, bien los podría haber pronunciado cualquiera de los vasallos de Asano en referencia al malvado maestro de ceremonias Kira Kōzuke-no-Suke:

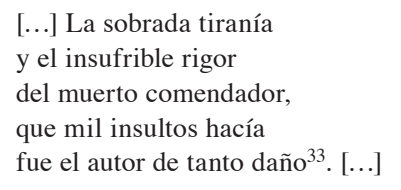

Y en grupo se vengan españoles y japoneses, sin que nadie haga de abanderado o destaque sobre los otros, como si los dramaturgos deseasen recalcar que es la masa la que, más allá de nombres o cargos, se resarce, profundamente herida en su honor, del que participan todos. En relación a esto nos dice otra vez Lope:

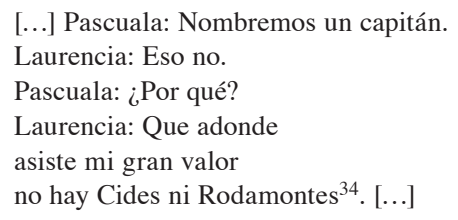

La diferencia sustancial entre ambos títulos reside en los finales (amable uno y trágico el otro), ya que mientras que en la obra ibérica los mismísimos Reyes Católicos aparecen en escena para perdonar a los habitantes de Fuenteovejuna por su crimen (es lógico que alguien tan elevado redima el asesinato de tan alto cargo), en la nipona se impone en todo el rígido código de honor del samurái (bushidō), que no acepta otra redención más que la del suicidio ritual (seppuku) para los samuráis. Las resultas, sin embargo, son parecidas, ya que la villa queda como guardiana del honor y los samuráis lo son del nombre y de la casa de su señor, a la que se deben por completo. En ambos países, aún hoy, Fuenteovejuna y los cuarenta y siete rōnin son recordados y honrados con afecto en dichos y en libros, ejemplos preclaros contra el abusador.

Déjenme terminar con las palabras del escritor argentino Jorge Luis Borges, quien en su libro Historia universal de la infamia nos dice:

[...] Este es el final de la historia de los cuarenta y siete hombres leales -salvo que no tiene final, porque los otros hombres, que no somos tan leales tal vez, pero que nunca perderemos del todo la esperanza de serlo, seguiremos honrándolos con palabras ${ }^{35}[\ldots]$.

Sean entonces estas pocas palabras mías una humilde ofrenda hacia los valientes samuráis de Ako y también para mis paisanos, retratados e inmortalizados por Lope, aquéllos que contra el no siempre noble acero usaron la no siempre resignada madera de sus bieldos.

\section{Notas}

1. Para las citas de esta obra en cuestión me remitiré siempre a la edición virtual disponible en la página web: http://www.edu.mec.gub.uy/biblioteca\%20digital/libros/L/Lope\%20de\%20Vega\%20-\%20El\%20ar te $\% 20$ nuevo $\% 20$ de $\% 20$ hacer\%20comedias.pdf

2. José, Juan de (ed.). 1971. El arte nuevo de hacer comedias en este tiempo de Lope de Vega. Madrid: CSIC. 
3. Haverbeck, Erwin.1988. "El arte nuevo de hacer comedias. Una nueva estética teatral”. Documentos Lingüísticos y Literarios. 14: 7-17.

4. Rozas, Juan Manuel. 1976. Significado y doctrina del «Arte nuevo» de Lope. Madrid: SGEL

5. Academia que no se ha identificado aún con seguridad. Algunos autores afirman que sería la creada en torno al poeta y músico Félix Arias Girón (¿-?-1630), amigo íntimo de Lope; otros aluden a la de Diego Gómez de Sandoval y Rojas (1584-1632) conde de Saldaña, a la que asistieron en más de una ocasión Lope y Cervantes entre otros insignes escritores.

6. Véase para estos asuntos el libro de Pérez, L. C. y F. Sánchez Escribano. 1961. Afirmaciones de Lope de Vega sobre preceptiva dramática. Madrid: CSIC (Anejos de «Revista de Literatura», nº 17).

7. Cervantes Saavedra, Miguel de. 1976. El ingenioso hidalgo don Quijote de la Mancha. Madrid: EspasaCalpe, cap. XLVIII: 305-306. Encontraremos un nuevo ataque a la estética propuesta por Lope de Vega en el capítulo XLVII de este mismo libro.

8. Nos referimos, como es lógico, a las conservadas o sobre las que tenemos noticias fiables, unas 350 en total, ya que el número de las que se le atribuyen llegaría a las 1500.

9. Para saber más sobre las interesantes propuestas dramáticas de este autor véase: Hermenegildo, Alberto. 1983. “Cristóbal de Virués y los signos teatrales del horror". Criticón. 23: 89-115. Sobre la reducción del número de actos de las comedias, Lope nos dice en su Arte nuevo:

El capitán Virués, insigne ingenio, puso en tres actos la comedia, que antes andaba en cuatro, como pies de niño que eran entonces niñas las comedias. (vv. 215-218)

10. Vega, Félix Lope de, Arte Nuevo, vs. 181-187.

11. Fernández, Jaime.1984. "Recuerdos de Naniwa (Naniga Miyage)”. Estudios de Asia y África. $64: 526$.

12. De hecho, su obra Ridens et Ridiculus quería ser el perdido Libro II de la Poética aristotélica.

13. El abuso de la espectacularidad escénica daría lugar en España a las denominadas "comedias de magia" y en Japón al Super Kabuki, creación del actor Ichikawa Ennosuke III. Ambos espectáculos comparten la constante de que la puesta en escena es casi más importante que el texto a representar.

14. 田人 en kanjis. Literalmente significa "habitantes de la ciudad".

15. Digo esto porque en muchas ocasiones los actores decidían representar un popurrí de las mejores escenas de distintas obras que sabían de antemano gustarían a su auditorio.

16. Aunque cambios como Oishi Kuranosuke por Oboshi Yuranosuke, en la obra Kanadehon Chüshingura, por ejemplo, no engañasen a nadie.

17. Lanzaco Salafranca, Federico. 2003. Los valores estéticos en la cultura clásica japonesa. Verbum: Madrid, 112. 
18. Vega, Lope de, Op. Cit.: 1-2, vs. 45-48.

19. Higashitani, Hidehito. 2009. "La venganza en el teatro japonés y los leales vasallo de Akõ". Revista de Occidente. 334: 71 .

20. Higashitani, Hidehito, Op., Cit.: 71 .

21. Lanzaco Salafranca, Federico, Op. Cit.: 114.

22. Higashitani, Hidehito, Op. Cit.: 71.

23. El shite sería el protagonista, personaje de alto rango que en la primera parte de la obra aparece con una identidad falsa, como un leñador o un campesino, para mostrar en la segunda parte su verdadera identidad, la de un guerrero o espíritu.

24. El waki es el deuteragonista del shite, casi siempre es un monje en peregrinación hacia un lugar santo. Rara vez lleva máscara y con sus palabras da pie a que el shite se exprese.

25. Trissino, Giovanni Giorgio. 1970. "La Poetica", Trattati di Poetica e Retorica del Cinquecento (Bernard 26.Weinberg ed.). vol. II. Bari: Laterza \& Figli, 63.

26. Vega, Lope de, Op. Cit.: 7, vv. 356-361.

27. Véase para este asunto el libro de Shaver, Ruth M. 1966. Kabuki Costume. Tokyo: Tuttle.

28. Por encima casi del lenguaje que, como ya vimos, era igual deliberadamente para unos y otros.

29. Véase, por ejemplo, el caso de obras tan famosas como El caballero de Olmedo o El mejor alcalde, el rey. Para este asunto léase el libro de Marín, Diego. 1958. La intriga secundaria en el teatro de Lope de Vega. México: Ed. De Andrea.

30. Y también del Bunraku o teatro tradicional de títeres, para el que fue originalmente compuesta en 1748.

31. Vega, Lope de. 2002. Fuenteovejuna (al cuidado de Rinaldo Froldi). Alicante: Biblioteca Virtual Miguel de Cervantes, 9 .

32. Vega, Lope de. Op.Cit.: Acto I, vv. 8-10.

33. Vega, Lope de. Op. Cit.: Acto III, vv. 2399-2403.

34. Vega, Lope de. Op. Cit.: Acto III, vv. 1846-1849.

35. Borges, Jorge Luis. 1997. "El incivil maestro de ceremonias Kotsuké no Suké”, Historia universal de la infamia. Madrid: Alianza, 67.

36. Aquí se recogen solo los títulos no mencionados ya en las pertinentes notas al texto. 


\section{Bibliografía $^{36}$}

Almazán Tomás, David. 1998. "Descubrimiento, difusión y valor del teatro japonés en España durante el primer tercio del siglo XX”. Artigrama. 13: 331-346.

Bisanti, Enrico. 1991. Vincenzo Maggi interprete "tridentino" della Poetica di Aristotele. Brescia: Ateneo di Brescia.

Bowers, Faubion. 1952. Japanese Theatre. New York: Hermitage House.

Buruma, Ian. 1984. Behind the Mask. New York: Meridian.

Cavaye, Roland. 2008. Kabuki: Teatro tradicional japonés. Gijón: Satori.

Diez Borque, José María. 1978. Sociedad y teatro en la España de Lope de Vega. Barcelona: Antonio Bosch.

Ernst, Earle. 1974. The Kabuki Theatre. Honolulu: University Press of Hawaii.

García Berrio, Antonio. 2006. Introducción a la Poética clasicista. Comentario a las "Tablas poéticas" de Cascales. Madrid: Cátedra.

González Vázquez, Carmen. 1996. "El léxico teatral de la Poética de Aristóteles en la versión latina de A. Riccoboni”. La recepción de las artes clásicas en el siglo XVI. Eustaquio Sánchez Salor, Luis Merino Jerez y Santiago López Moreda (eds.). Cáceres: Servicio de Publicaciones de la Universidad de Extremadura, 445-451.

Gunji, Masakatsu. 1986. Kabuki. Tokyo: Kodansha International.

Herrera Montero, Bernal. 1989. "Fuenteovejuna de Lope de Vega y el Maquiavelismo". Criticón. 45: 131-153.

Hume, Nancy G. (ed.). 1995. Japanese aesthetics and culture. New York: State University of New York Press.

José Prades, Juana de. 1966. "El «Arte nuevo de hacer comedias» de Lope de Vega (un ensayo bibliográfico)". Segismundo. 3: 45-55.

Kirschner, Teresa. 1979. El protagonista colectivo en Fuenteovejuna. Salamanca: Universidad de Salamanca.

Leiter, Samuel. 1979. Kabuki Encyclopedia. Connecticut: Greenwood Press. 
Molina Sánchez, Manuel. 1996. "Poéticas latinas españolas de los siglos XVI y XVII: una aproximación a su estudio". La recepción de las artes clásicas en el siglo XVI. Eustaquio Sánchez Salor, Luis Merino Jerez y Santiago López Moreda (eds.). Cáceres: Servicio de Publicaciones de la Universidad de Extremadura, 497-506.

Orozco, E. 1978. ¿Qué es el «Arte nuevo» de Lope de Vega? Anotación previa a una reconsideración crítica. Salamanca: Universidad de Salamanca.

Pérez, L. C. y F. Sánchez Escribano. 1961. Afirmaciones de Lope de Vega sobre preceptiva dramática. Madrid: CSIC (Anejos de «Revista de Literatura», nº 17).

Pueo, Juan Carlos. 1994/95. "Dos interpretaciones de Aristóteles: Robortello y Maggi ante la teoría de la comedia”. Tropelías. 5-6: 299-313.

Ridens et Ridiculus. Vincenzo Maggi y la teoría humanista de la risa. Zaragoza: Colección Trópica (Anexos de Tropelías, ${ }^{\circ} 8$ ).

Sánchez Escribano, F. y A. Porqueras. 1972. Preceptiva dramática española del Renacimiento y del Barroco. Madrid: Gredos.

Scott, Adolphe Clarence. 1999. The Kabuki Theatre of Japan. New York: Dover.

Watsuji, Tetsuro. 1973. El hombre y su ambiente. Madrid: Castellote.

Yoshida, Chiaki. 1977. Kabuki: The Resplendent Theatre of Japan. Tokyo: The Japan Times. 
